(c) American Dairy Science Association, 2006.

\title{
Dry Period Length to Maximize Production Across Adjacent Lactations and Lifetime Production
}

\author{
M. T. Kuhn, J. L. Hutchison, and H. D. Norman \\ Animal Improvements Program Laboratory, Agricultural Research Service, USDA, Beltsville, MD 20705-2350
}

\begin{abstract}
The primary objectives of this research were to determine the dry period lengths that maximize production across adjacent lactations and also dry period length that maximizes lifetime yield. Effect of days dry (DD) after lactations 1 through 3 were determined separately for both adjacent lactation sums and lifetime yield. Field data, collected through the Dairy Herd Improvement Association, on US Holstein cows first calving between January 1997 and January 2004 were utilized. Lifetime records were restricted to cows first calving no later than December 1999. Actual lactation yields, in contrast to standardized records, were used to calculate lactation sums and lifetime records. Herds were required to be on test for the entire period to avoid partial records. Another important edit was that actual calving dates had to agree with expected calving dates, based on reported days open, within $10 \mathrm{~d}$. This edit ensured that the producer knew, at least at one point in time, when the cow was going to calve. Cow effects were corrected for in both the adjacent lactation and lifetime analyses. The minimum DD to maximize production across adjacent lactations depended on parity. For yield across first and second lactations, there was little loss in production with a minimum of 40 to $45 \mathrm{DD}$. Longer dry periods ( 55 to $65 \mathrm{DD}$ ) were required after second and third lactations however, presumably due to the lower persistency of second and later lactation cows. Lifetime production was maximized by 40 to $50 \mathrm{DD}$ after first lactation and 30 to $40 \mathrm{DD}$ after second and later lactations. Fewer DD were required to maximize lifetime yield than adjacent lactation yield because cows with fewer DD also had more lifetime days in milk. Although dry periods of 30 to $40 \mathrm{~d}$ can be used after second and later lactations without cost in lifetime yield, their benefit to lifetime production is minimal. Dry periods shorter than $30 \mathrm{~d}$ or longer than $70 \mathrm{~d}$ are costly to lifetime yield and should be avoided. Dry peri-
\end{abstract}

Received November 9, 2005.

Accepted December 12, 2005.

${ }^{1}$ Corresponding author: mkuhn@aipl.arsusda.gov ods longer than $80 \mathrm{~d}$ are even more costly than dry periods less than $30 \mathrm{~d}$.

Key words: days dry, lifetime production

\section{INTRODUCTION}

Length of dry period has become a topic of renewed interest, as evidenced by numerous popular press articles (Annen et al., 2003; Linderoth, 2003; Rastani and Grummer, 2003; Bachman, 2004; Grummer, 2004; Mohr, 2004). Past research (e.g., Coppock et al., 1974; Dias and Allaire, 1982; Funk et al., 1987; Sorenson and Enevoldsen, 1991; Remond et al., 1992; Makuza and McDaniel, 1996) has almost unanimously supported the conclusion that dry periods less than $60 \mathrm{~d}$ result in lost production in the subsequent lactation. In more recent research, one experiment (Gulay et al., 2003) found essentially no mean difference in subsequent lactation milk yield between cows with $60 \mathrm{~d}$ dry (DD) and those with shortened dry periods; one study (Bachman, 2002) actually reported a higher mean for cows with $\mathrm{DD}<60$. However, most recent research (Annen et al., 2004; Madsen et al., 2004; Gulay et al., 2005; Kuhn et al., 2005b; Rastani et al., 2005) has supported past research, finding lower mean milk yield for cows with fewer than $60 \mathrm{DD}$, although, as indicated by results from Kuhn and Hutchison (2005), sample sizes were sometimes too small to declare differences statistically significant.

While both past and current research support the conclusion of lower yield in lactations following dry periods shorter than $60 \mathrm{~d}$, it is also true that dry off causes lost yield in the previous lactation. Yield gained in the previous lactation due to longer lactation length may more than offset yield lost in the subsequent lactation caused by $\mathrm{DD}<60$. However, there is little research as to the dry period length that maximizes production across adjacent lactations. An older study by Dias and Allaire (1982) appears to be the only published research that directly investigated dry period length to maximize production across adjacent lactations. In general, they found that dry periods of at least $60 \mathrm{~d}$ were needed to maximize daily yield across 2 lactations, except for cows with long days open and low production. However, mean lactational milk yield for US Holsteins has in- 
creased by more than $4,000 \mathrm{~kg}$ since 1980 (Animal Improvement Programs Laboratory, 2005). Thus, modern dairy cows are almost certainly producing at higher levels at the end of lactation than cows from 20 to 30 yr ago and, therefore, dry period length to maximize yield across lactations may have changed over time.

Although knowing the dry period length that maximizes production across adjacent lactations would certainly be beneficial in making recommendations to dairy producers and add to the understanding of the effects of dry period length, even that would not completely address the question of appropriate or phenotypically optimum DD if dry period length also affected number of lactations. If, for example, $30 \mathrm{DD}$ after first lactation maximized yield across first and second lactations but cows with 30 DD were culled much more intensely toward the end of second lactation, then 30 DD may not be optimum. Such a cost in lifetime yield, however, would not be detected by a mere examination of production across adjacent lactations. Determination of $\mathrm{DD}$ to maximize lifetime yield would provide more complete information than DD maximizing yield across adjacent lactations. Not only would lifetime yield account for production lost in preceding lactations due to dry off, but also any detrimental (or beneficial) effects of DD on productive life. Research to determine longterm consequences of shortened dry periods, and in particular effects on lifetime production, appears to be quite sparse. Remond et al. (1997) appears to be the only study to even consider the question of lifetime effects of DD, although they encountered some difficulties in their small-scale designed trial, which made conclusions difficult to draw.

The objectives of this research were to determine DD that maximizes milk yield across adjacent lactations and the dry period length that maximizes lifetime milk, fat, and protein yields. Part of the objective was also to determine if these phenotypically optimum dry period lengths depended on parity. Even if $60 \mathrm{DD}$, for example, were required after first lactation to maximize the sum of first- and second-lactation yields, a shorter dry period might maximize the combined yield after later parities. The effect of DD on lifetime yield was also studied separately for each parity. Effects of dry period length on lifetime DIM were also estimated.

\section{MATERIALS AND METHODS}

\section{Data}

Source of Data and Calculation of Lactational Yields. Field data collected through DHI and extracted from the Animal Improvement Programs Laboratory national database were used for analysis. For determination of DD to maximize yield across adjacent lacta-
Table 1. Arithmetic means, by lactation, for actual milk yield $(\mathrm{kg})$ and DIM for cows in adjacent lactation analyses

\begin{tabular}{lll}
\hline Lactation & Milk & DIM \\
\hline 1 & 10,152 & 361 \\
2 & 11,126 & 346 \\
3 & 11,342 & 338 \\
4 & 11,270 & 335 \\
5 & 11,027 & 330 \\
\hline
\end{tabular}

tions, lactational milk yields were summed across adjacent parities: lactations 1 and 2 (Sum12), 2 and 3 (Sum23), and 3 and 4 (Sum34) and each of the 3 sums were analyzed separately to allow for the possibility of different DD effects for different lactations. Lifetime yields were computed as the sum of all lactation records. Actual lactation yields, in contrast to $305-\mathrm{d}$ or $305-\mathrm{d}$ mature equivalent records, were used for both sums across adjacent lactations and for lifetime yields. The only standardization done to the lactational records was to a twice-daily milking basis. Records less than $305 \mathrm{~d}$ were not extended to $305 \mathrm{~d}$ and all production beyond $305 \mathrm{~d}$ was included. The only restriction put on length of lactation was that lactations more than $2 \mathrm{yr}$ long were deleted.

Actual yields were used instead of 305-d or 305-d mature equivalent yields for 2 reasons. First, farmers are paid for actual production, not extended or mature equivalent production. Secondly, use of extended records could conceal the exact variation that needs to be discovered. If a short dry period, for example, caused problems in the subsequent lactation that resulted in early culling or earlier dry off, then extending records to a 305-d basis would tend to reduce or eliminate that effect. If short lactations are unrelated to DD, then they will occur randomly across dry periods and cause no bias in the analyses. Previous research (Kuhn et al., 2005b) has, in fact, shown that use of extended records does result in underestimation of DD effects on subsequent lactation milk yield, which supports actual production as a more judicious choice of variable for study of DD effects in this research. Thus, actual lactation yields were used in this study and were calculated from test-day records using the test-interval method (Sargent et al., 1968) and the adjustment factors of Shook et al. (1980). Arithmetic means of actual lactational yields and DIM are given in Table 1 for the first 5 lactations of cows used in the adjacent lactation analyses.

Records used for analysis of lifetime yields were a subset of the data used for determination of DD to maximize yield across adjacent lactations. General edits applied to data for use in the adjacent lactation analyses, therefore, applied to the lifetime analyses as well. 
Thus, data for the analysis of sums across adjacent lactations will be described first, followed by the additional edits (subsetting) needed for the lifetime analyses.

Milk Yield Sums Across Adjacent Lactations. Only records of US Holstein cows first calving after January 1997 were included. Test-day records past 305 d were not kept prior to 1997 and, therefore, actual yields could not be computed for lactations prior to 1997. For each 2-lactation sum, the latter record (e.g., lactation 2 for Sum12) was required to have been initiated no later than January 2004, which allowed cows a minimum of $1.5 \mathrm{yr}$ to complete their records, because data were extracted in August 2005.

To avoid incomplete records, herds were required to be on continuous test from the time their data was initially included. For most herds, this meant being on continuous test from January 1997 to August 2005. However, the date at which complete lactation information was available varied somewhat across dairy records processing centers because not all centers began sending complete lactation information at the same time. Thus, the January 1997 lower limit for date of inclusion had to be moved forward for some herds. This change in edit affected western herds the most. Cows were also included only if they initiated their first lactation on or after the date of first inclusion for their herd.

Records initiated by abortion were excluded as well as cows known to be embryo transfer donors because either of these could lead to dry periods or lactations of abnormal length. Days dry were required to be between 0 and $120 \mathrm{~d}$ in length. Records where DD was more than $120 \mathrm{~d}$ were deleted. The restriction to dry periods $\leq 120 \mathrm{~d}$ had no effect on the results for other DD categories and also accounted for only a small portion of the data. The edit was enforced simply to exclude potentially peculiar cows.

Another important edit on lactation records was that the expected calving date (based on last reported days open) and the actual calving date had to agree within 10 d. Some researchers (Bachman and Schairer, 2003; Grummer and Rastani, 2004) have argued that analyses using DHI data are "biased" because the short dry periods included are primarily those that are unplanned and if the cow had a known calving date, it would have been managed differently for the short DD. This edit ensured that the farmer knew when the cow was going to calve because, in effect, the producer reported it to DHI.

Categories for DD were formed for analysis. The 16 categories used for analysis are defined in Table 2 along with the number of records in each category for each lactational sum. Categories with small intervals are most desirable because they portray the most informa-
Table 2. Number of cows for the analysis of sums across adjacent lactations, by days dry (DD) category and parity ${ }^{1}$

\begin{tabular}{llrrr}
\hline $\begin{array}{l}\text { DD } \\
\text { category }\end{array}$ & DD & \multicolumn{1}{c}{ N12 } & \multicolumn{1}{c}{ N23 } & \multicolumn{1}{c}{ N34 } \\
\hline 1 & $0-10$ & 3,142 & 1,010 & 416 \\
2 & $11-20$ & 1,949 & 548 & 199 \\
3 & $21-30$ & 5,279 & 1,574 & 656 \\
4 & $31-35$ & 6,457 & 2,018 & 762 \\
5 & $36-40$ & 12,968 & 4,562 & 1,643 \\
6 & $41-45$ & 26,693 & 9,870 & 3,790 \\
7 & $46-50$ & 52,329 & 19,831 & 7,330 \\
8 & $51-55$ & 86,638 & 34,088 & 12,347 \\
9 & $56-60$ & 101,609 & 41,890 & 15,609 \\
10 & $61-65$ & 75,269 & 33,454 & 12,616 \\
11 & $66-70$ & 36,793 & 18,406 & 7,161 \\
12 & $71-80$ & 24,252 & 15,413 & 6,335 \\
13 & $81-90$ & 10,680 & 8,761 & 3,733 \\
14 & $91-100$ & 6,642 & 6,135 & 2,496 \\
15 & $101-110$ & 4,434 & 4,254 & 1,723 \\
16 & $111-120$ & 3,236 & 3,077 & 1,163 \\
& Total & 458,370 & 204,891 & 77,979 \\
\hline
\end{tabular}

${ }^{1} \mathrm{~N} 12$ = Number of cows for sum across first and second lactations; N23 = Number of cows for sum across second and third lactations; N34 = Number of cows for sum across third and fourth lactations.

tion in regard to response to increasing or decreasing DD. However, both short and long dry periods were less frequent than more midrange dry period lengths. Therefore, 10-d intervals were used for DD $<31$ and DD $>70$, to maintain reasonable sample sizes, and 5d intervals were used for dry periods between 31 and $70 \mathrm{~d}$. After edits, there were, for example, 458,370 records for Sum12 (Table 2), from 4,173 herds in 44 states.

Lifetime Data. For the lifetime analyses, only herds on continuous test from January 1997 to August 2005 were included. Furthermore, only cows first calving in 1997,1998 , or 1999 were included in the lifetime analysis. The cutoff date of December 1999 ensured nearly complete lifetime information on all cows included.

All lactations of a cow had to pass each edit in order for the cow to be included. If, for example, a cow had one lactation in which its expected calving date was different than the observed calving date, the cow was eliminated from the analysis. This was necessary to compute lifetime yields and yet still enforce the lactational edits. If even a single lactation for a given cow was removed by an edit, then its lifetime yield could not be computed. After edits, there were 159,904 cows, for lifetime analysis of DD between first and second lactations (Table 3), from 4,170 herds and 44 states.

Fewer DD categories were used for the lifetime analyses (Table 3) than for determination of DD to maximize production across adjacent lactations (Table 2) to maintain DD subclass sample sizes. The categories used for analysis represented a compromise between subclass sample size and the amount of detail in describing the relationship between DD and lifetime yield. Prelimi- 
Table 3. Number of cows for analysis of lifetime milk yield, by days dry (DD) category and parity ${ }^{1}$

\begin{tabular}{llrrr}
\hline $\begin{array}{l}\text { DD } \\
\text { category }\end{array}$ & DD & \multicolumn{1}{c}{ N1 } & \multicolumn{1}{c}{ N2 } & \multicolumn{1}{c}{ N3 } \\
\hline 1 & $0-20$ & 1,359 & 450 & 283 \\
2 & $21-30$ & 1,624 & 553 & 334 \\
3 & $31-40$ & 6,338 & 2,531 & 1,291 \\
4 & $41-50$ & 26,621 & 12,444 & 6,384 \\
5 & $51-60$ & 65,503 & 33,601 & 16,721 \\
6 & $61-70$ & 39,610 & 23,633 & 12,138 \\
7 & $71-80$ & 9,023 & 7,314 & 4,022 \\
8 & $81-90$ & 4,111 & 4,328 & 2,390 \\
9 & $91-100$ & 2,573 & 3,051 & 1,646 \\
10 & $101-110$ & 1,785 & 2,181 & 1,141 \\
11 & $111-120$ & 1,357 & 1,525 & 786 \\
& Total & 159,904 & 91,611 & 47,136 \\
\hline
\end{tabular}

${ }^{1} \mathrm{~N} 1=$ Number of cows with a DD between first and second lactations; N2 = Number of cows with a DD between second and third lactations; N3 = Number of cows with a DD between third and fourth lactations.

nary analyses on lifetime yield, using more DD categories with shorter intervals, indicated the final intervals chosen for analysis adequately displayed the effects of DD on lifetime production.

The high phenotypic correlations amongst milk, fat, and protein yield (Welper and Freeman, 1992) would imply the same general patterns of DD effects for fat and protein yields as for milk yield. Therefore, in addressing the question of dry period length to maximize production across adjacent lactations, milk yield only was analyzed as a dependent variable. In contrast, DD effects on lifetime fat and protein yield were estimated in addition to those for milk yield so as to make the actual estimates for lifetime fat and protein available for researchers interested in determining an economically optimum dry period. The effects of dry period length on lifetime DIM were estimated as well.

Arithmetic means were 21,372 kg for Sum12; 22,812 $\mathrm{kg}$ for Sum23; and 23,135 kg for Sum34. The overall arithmetic mean lifetime yield for cows with at least 2 lactations, and thus included in the lifetime analysis, was $32,784 \mathrm{~kg}$ and mean lifetime DIM was 1,049 .

\section{Models for Analysis}

Determination of DD to Maximize Milk Yield Across Adjacent Lactations. The fixed effects, linear model used for analysis of Sum12, Sum23, and Sum34 was:

$$
\begin{gathered}
\mathrm{y}^{*}=\mathrm{HY}+\text { YR-ST-MO }+\mathrm{DD}_{i}+\beta_{1} \times \text { Age } \\
+\beta_{2} \times \mathrm{Age}^{2}+\mathrm{e}
\end{gathered}
$$

where $\mathrm{y}^{*}$ was the milk yield sum (kg) across adjacent lactation records adjusted for cow effects, $\mathrm{HY}$ was herd- year of calving for the lactation preceding the dry period (e.g., lactation 1 for Sum12), YR-ST-MO was year-statemonth of calving for the lactation preceding the dry period, DD $i$ was days dry between first and second lactations (DD1) for Sum12, second and third lactations (DD2) for Sum23, or third and fourth lactations (DD3) for Sum34, and Age was age at calving in the lactation preceding the dry period, fit as a linear and quadratic covariate with regression coefficients $\beta_{1}$ and $\beta_{2}$.

The prior adjustment for cow effects was done simply by subtracting estimated cow effects (sum of breeding value and permanent environmental effects) from the 2-lactation sums. Cow effects were estimated using a single trait, repeatability animal model, which was the same as Model [1] but with animal and permanent environmental effects included as well. All lactation sums (Sum12, Sum23, and Sum34) were analyzed simultaneously for estimation of cow effects. Cows were required to have first lactation to be included but did not have to have more than a single lactation. Following the approach of Kuhn and Hutchison (2005), cows with only a single lactation were given their own unique DD category. Cows with only a single lactation were not, of course, used in fitting Model [1] because they would not contribute to estimates of DD effects but were included in the estimation of cow effects to avoid selection bias.

Previous days open was included in a preliminary analysis but was not included in the final models for analysis. The primary effect of including previous days open in the model was to increase differences for long dry periods. In effect, inclusion of days open in the model standardized records for lactation length, which was certainly not desirable in this study. The objective was to determine if the late lactation production of cows with shorter dry periods would offset losses in subsequent lactation yield and inclusion of days open in the model would have been antagonistic to that purpose.

Lifetime. Three models were used to estimate DD effects on lifetime production, corresponding to 3 different lactations:

$$
\begin{gathered}
\mathrm{y}=\mathrm{HY} 1+\mathrm{DD} 1+\beta_{1} \times \mathrm{LR} 1+\beta_{2} \times \text { Age } 1 \\
+\beta_{3} \times \mathrm{Age}^{2}+\mathrm{e} \\
\mathrm{y}=\mathrm{HY} 1+\mathrm{DD} 1+\mathrm{DD} 2+\beta_{1} \times \mathrm{LR} 2 \\
+\beta_{2} \times \mathrm{Age} 1+\beta_{3} \times \mathrm{Age}^{2}+\mathrm{e} \\
\mathrm{y}=\mathrm{HY} 1+\mathrm{DD} 1+\mathrm{DD} 2+\mathrm{DD} 3 \\
+\beta_{1} \times \mathrm{LR} 3+\beta_{2} \times \mathrm{Age} 1+\beta_{3} \times \mathrm{Age}^{2}+\mathrm{e}
\end{gathered}
$$

where y was lifetime milk, fat, protein $(\mathrm{kg})$, or DIM record, HY1 was herd-year of first calving, LR1 through 
LR3 were the lactational records for milk, fat or protein for parities 1 through 3, respectively, and Age1 was age at first calving. Estimates for effects of DD1 were from [2], for DD2 from [3], and from [4] for DD3. Previous lactation record was dropped from the model for lifetime DIM.

Use of estimated breeding values as a prior correction for cow effects in the lifetime analyses was complicated by the fact that 1) DD must be in the model for estimation of cow effects to avoid having the DD effect partitioned into the cow effect, and 2) lifetime yields had more than one associated dry period length. Including an extra "missing" category for each DD appeared to result in bias in the estimated breeding values, presumably due to confounding across the various unknown categories (the unknown category for DD3, for example, would contain cows with no dry periods as well as cows with 1,2 , and no dry periods and cows with no dry period would also be in the missing category for DD1 and DD2). Thus, cow effects were corrected for in the lifetime analyses by inclusion of the previous lactation record (previous to the dry period of interest), rather than using a prior correction as was done in the adjacent lactation analyses. A small simulation confirmed that inclusion of the previous lactation record would provide estimates of DD effects that were unbiased by cow effects, even when DD is correlated with previous lactation yield. This is similar to the findings of Kuhn and Hutchison (2005) for estimation of DD effects on subsequent lactation yield.

Preliminary analyses clearly indicated that fitting $\mathrm{DD}$ as a categorical variable, rather than as a linear and quadratic covariate, allowed for a much better description of DD effects on lifetime yields. Regression forces the relationship between the 2 variables to conform to a particular pattern (e.g., symmetric about the maximum point for a quadratic regression), which, as the results will show, was not the case.

\section{RESULTS AND DISCUSSION}

\section{Sum Across Adjacent Lactations}

Table 4 contains the results for effects of DD across adjacent lactations. The differences in means presented in Table 4 are expressed relative to a 61- to 65-d dry period; that is, as DD category $y_{i}-\mathrm{DD}$ category $_{10}$ for $\mathrm{i}=$ 1 to 16 . In regard to interpretation, the -419 in the first row of the first column for Sum12 indicates, for example, that cows with 0 to $10 \mathrm{DD}$ produce $419 \mathrm{~kg}$ less milk across lactations 1 and 2 than cows with 61 to 65 DD. Likewise, the -981 in the first row for Sum23 means that cows given 0 to $10 \mathrm{DD}$ after second lactation produce $981 \mathrm{~kg}$ less milk for lactations 2 and 3 combined than cows given 61 to $65 \mathrm{DD}$.
The first general result to note from Table 4 is that production losses across lactations 1 and 2, associated with dry periods less than $60 \mathrm{~d}$, were considerably less than for later parities. This is likely due to the greater persistency of first-lactation cows (Stanton et al., 1992). Thus, first-lactation cows more readily compensate for milk loss in the subsequent (second) lactation, due to shortened dry periods, because of higher production at the end of the preceding (first) lactation.

Although most differences were statistically significant, milk loss for first and second lactations combined was small after a minimum of $41 \mathrm{DD}$. A dry period of 40 to $45 \mathrm{~d}$ appears adequate to maximize milk yield across first and second lactations. In contrast, a minimum of $50 \mathrm{DD}$ after second and later lactations is needed to maximize milk yield across adjacent lactations.

Also noteworthy is the loss in total milk yield across lactations associated with dry periods longer than 60 $\mathrm{d}$ after second and later lactations, which is in contrast to the effect of long DD for Sum12. Long dry periods are associated with long days open (Kuhn et al., 2005a) and also with lower yield in subsequent lactation (Kuhn et al., 2005b). Thus, in first lactation it appears that cows continue to produce enough in late lactation to offset the production loss in second lactation, whereas the production for older cows declines to a point, again in late lactation, at which losses in subsequent lactation are not mitigated in the lactation preceding the dry period.

\section{Lifetime Yield and Productive Life}

Results for lifetime milk yield are presented in Table 5. Results are expressed relative to (as a difference from) the minimum DD (category) to maximize lifetime yield. As an example of interpretation, the $-2,637 \mathrm{~kg}$ in Table 5 for DD1, category 1 means that cows with 0 to $20 \mathrm{DD}$ after first lactation produce $2,637 \mathrm{~kg}$ less milk in their lifetimes than cows with 41 to $50 \mathrm{DD}$ after first lactation. Effects of DD on lifetime fat and protein yields are given in Tables 6 and 7 and follow the same general patterns as those for milk yield.

Losses in lifetime production associated with dry periods $\leq 30 \mathrm{~d}$ were substantial, regardless of lactation. Results indicated little benefit for dry periods $<60 \mathrm{~d}$ after first lactation. There was essentially no loss in lifetime yield for first-lactation dry periods of only 41 to $50 \mathrm{~d}$ but also no gain. In contrast, dry periods of 31 to $40 \mathrm{~d}$ may be beneficial after second and later lactations. Maximum lifetime production occurred with 31 to $40 \mathrm{DD}$ after second and third lactations. Although differences between 31 and 60 DD were not statistically 
Table 4. Effects (kg) of days dry (DD) on adjacent lactation sums, expressed relative to category $10^{1,2}$

\begin{tabular}{|c|c|c|c|c|c|c|c|}
\hline \multirow{2}{*}{$\begin{array}{l}\text { DD } \\
\text { category }\end{array}$} & \multirow[b]{2}{*}{ DD } & \multicolumn{2}{|c|}{ Sum12 } & \multicolumn{2}{|c|}{ Sum23 } & \multicolumn{2}{|c|}{ Sum34 } \\
\hline & & $\mathrm{DD}_{\mathrm{i}}-\mathrm{DD}_{10}$ & SE & $\mathrm{DD}_{\mathrm{i}}-\mathrm{DD}_{10}$ & $\mathrm{SE}$ & $\mathrm{DD}_{\mathrm{i}}-\mathrm{DD}_{10}$ & $\mathrm{SE}$ \\
\hline 1 & $0-10$ & $-419 * * *$ & 41 & $-981 * * *$ & 80 & $-688^{* * *}$ & 173 \\
\hline 2 & $11-20$ & $-572 * * *$ & 51 & $-1,039 * * *$ & 108 & $-1,027 * * *$ & 249 \\
\hline 3 & $21-30$ & $-264 * * *$ & 32 & $-675 * * *$ & 65 & $-658 * * *$ & 139 \\
\hline 4 & $31-35$ & $-148 * * *$ & 29 & $-249 * * *$ & 57 & $-294 *$ & 128 \\
\hline 5 & $36-40$ & $-101 * * *$ & 21 & $-200 * * *$ & 40 & $-300 * * *$ & 89 \\
\hline 6 & $41-45$ & $-59 * * *$ & 16 & $-97 * * *$ & 29 & $-167 * *$ & 63 \\
\hline 7 & $46-50$ & $-34 * *$ & 13 & $-126 * * *$ & 22 & $-253 * * *$ & 49 \\
\hline 8 & $51-55$ & $-35^{* *}$ & 11 & $-67 * * *$ & 19 & $-84 *$ & 41 \\
\hline 9 & $56-60$ & $-23 *$ & 10 & -28 & 17 & -36 & 38 \\
\hline 10 & $61-65$ & 0 & 0 & 0 & 0 & 0 & 0 \\
\hline 11 & $66-70$ & 23 & 14 & $-107 * * *$ & 22 & -20 & 47 \\
\hline 12 & $71-80$ & 26 & 16 & $-239 * * *$ & 24 & $-230 * * *$ & 50 \\
\hline 13 & $81-90$ & 33 & 22 & $-277 * * *$ & 29 & $-196 * *$ & 61 \\
\hline 14 & $91-100$ & $69 *$ & 28 & $-453 * * *$ & 34 & $-304 * * *$ & 72 \\
\hline 15 & $101-110$ & 44 & 33 & $-494 * * *$ & 39 & $-175^{*}$ & 84 \\
\hline 16 & $111-120$ & 13 & 39 & $-504 * * *$ & 46 & $-465 * * *$ & 100 \\
\hline
\end{tabular}

${ }^{1}$ Sum $12=$ sum of actual yields for lactations 1 and 2; Sum23 = sum of actual yields for lactations 2 and 3 ; Sum34 = sum of actual yields for lactations 3 and 4 .

${ }^{2} \mathrm{DD}_{\mathrm{i}}-\mathrm{DD}_{10}=$ Mean yield for $\mathrm{DD}$ category $\mathrm{i}_{\mathrm{i}}$ minus mean yield for $\mathrm{DD}$ category ${ }_{10}, \mathrm{i}=1$ to 16 . $P$-values correspond to a two-tailed $t$-test for the null hypothesis of no difference between category $i$ and category 10.

$* P<0.05 ; * * P<0.01 ; * * * P<0.001$.

significant, they were consistent across lactations 2 and 3 and, within lactation, the 200 - to $300-\mathrm{kg}$ losses for 41 to $60 \mathrm{DD}$ contributed to a consistent overall pattern relative to the other DD categories. Thus, in spite of $P$ values greater than 0.1 , it is reasonable to conclude that at least some minor losses in lifetime yield occur when dry period length is between 40 and $60 \mathrm{~d}$ after second and later lactations.

Losses associated with dry periods between 41 and $60 \mathrm{~d}$ (200 to $300 \mathrm{~kg}$ ) were minor but become at least somewhat relevant when accumulated across all cows in a herd. In a 100 -cow herd, for example, a $250-\mathrm{kg} / \mathrm{cow}$ loss in lifetime milk yield means $25,000-\mathrm{kg} /$ herd less lifetime milk yield or, with an average of 2.5 lactations/ cow and a 420-d average CI, roughly $8,700 \mathrm{~kg} / \mathrm{h}$ erd per yr. At $\$ 13.00 /$ cwt, this translates to about $\$ 2,500 / y r$ for a 100-cow herd. The main point, however, is simply that dry periods after second and later lactations can be shortened to a minimum of 31 to $40 \mathrm{~d}$ without loss in lifetime production. Thus, some dairy producers may benefit from shorter DD for second and later lactation cows if such a practice simplified management or im-

Table 5. Effects (kg) of days dry after first lactation (DD1), second lactation (DD2), and third lactation (DD3) on lifetime milk yield, expressed relative to minimum DD category needed to maximize yield

\begin{tabular}{|c|c|c|c|c|c|c|c|}
\hline \multirow{2}{*}{$\begin{array}{l}\text { DD } \\
\text { category }\end{array}$} & \multirow[b]{2}{*}{$\mathrm{DD}$} & \multicolumn{2}{|c|}{$\mathrm{DD} 1^{1}$} & \multicolumn{2}{|c|}{$\mathrm{DD} 2^{2}$} & \multicolumn{2}{|c|}{$\mathrm{DD}^{2}$} \\
\hline & & $\mathrm{DD}_{\mathrm{i}}-\mathrm{DD}_{4}$ & $\mathrm{SE}$ & $\mathrm{DD}_{\mathrm{i}}-\mathrm{DD}_{3}$ & $\mathrm{SE}$ & $\mathrm{DD}_{\mathrm{i}}-\mathrm{DD}_{3}$ & $\mathrm{SE}$ \\
\hline 1 & $0-20$ & $-2,637 * * *$ & 453 & $-3,455^{* * * *}$ & 765 & $-2,421$ *** & 932 \\
\hline 2 & $21-30$ & $-1,039 *$ & 416 & $-1,570 *$ & 686 & $-1,437$ & 839 \\
\hline 3 & $31-40$ & -439 & 225 & 0 & 0 & 0 & 0 \\
\hline 4 & $41-50$ & 0 & 0 & -216 & 320 & -215 & 411 \\
\hline 5 & $51-60$ & 29 & 119 & -277 & 311 & -309 & 400 \\
\hline 6 & $61-70$ & $-386 * *$ & 134 & $-831 * *$ & 317 & -619 & 408 \\
\hline 7 & $71-80$ & $-2,432 * * *$ & 197 & $-2,792 * * *$ & 343 & $-2,499 * * *$ & 438 \\
\hline 8 & $81-90$ & $-3,726$ **** & 267 & $-3,409 * * *$ & 370 & $-3,230$ *** & 471 \\
\hline 9 & $91-100$ & $-4,467 * * *$ & 327 & $-4,286 * * *$ & 395 & $-3,148 * * *$ & 504 \\
\hline 10 & $101-110$ & $-4,622 * * *$ & 386 & $-4,231 * * *$ & 428 & $-3,784 * * *$ & 549 \\
\hline 11 & $111-120$ & $-4,736$ *** & 439 & $-4,555 * * *$ & 472 & $-4,605^{* * * *}$ & 609 \\
\hline
\end{tabular}

${ }^{1} \mathrm{DD}_{\mathrm{i}}-\mathrm{DD}_{4}=$ Mean yield for DD category $\mathrm{i}_{\mathrm{i}}$ minus mean yield for DD category, $\mathrm{i}=1$ to $11 . P$-values correspond to a two-tailed $t$-test for the null hypothesis of no difference between category $i$ and category 4 .

${ }^{2} \mathrm{DD}_{\mathrm{i}}-\mathrm{DD}_{3}=$ Mean yield for $\mathrm{DD}$ category $_{\mathrm{i}}$ minus mean yield for $\mathrm{DD}$ category ${ }_{3}, \mathrm{i}=1$ to 11 . $P$-values correspond to a two-tailed $t$-test for the null hypothesis of no difference between category $i$ and category 3 .

$* P<0.05 ; * * P<0.01 ; * * * P<0.001$. 
Table 6. Effects (kg) of days dry after first lactation (DD1), second lactation (DD2), and third lactation (DD3) on lifetime fat yield, expressed relative to minimum DD category needed to maximize yield

\begin{tabular}{|c|c|c|c|c|c|c|c|}
\hline \multirow{2}{*}{$\begin{array}{l}\text { DD } \\
\text { category }\end{array}$} & \multirow[b]{2}{*}{ DD } & \multicolumn{2}{|c|}{$\mathrm{DD} 1^{1}$} & \multicolumn{2}{|c|}{$\mathrm{DD} 2^{2}$} & \multicolumn{2}{|c|}{$\mathrm{DD}^{2}$} \\
\hline & & $\mathrm{DD}_{\mathrm{i}}-\mathrm{DD}_{4}$ & SE & $\mathrm{DD}_{\mathrm{i}}-\mathrm{DD}_{3}$ & SE & $\mathrm{DD}_{\mathrm{i}}-\mathrm{DD}_{3}$ & $\mathrm{SE}$ \\
\hline 1 & $0-20$ & $-81^{* * *}$ & 17 & $-120 * * *$ & 30 & $-87^{*}$ & 38 \\
\hline 2 & $21-30$ & -30 & 16 & $-60 *$ & 26 & -56 & 32 \\
\hline 3 & $31-40$ & -16 & 9 & 0 & 0 & 0 & 0 \\
\hline 4 & $41-50$ & 0 & 0 & -6 & 12 & -7 & 16 \\
\hline 5 & $51-60$ & 4 & 5 & -16 & 12 & -10 & 15 \\
\hline 6 & $61-70$ & -6 & 5 & $-30 *$ & 12 & -15 & 16 \\
\hline 7 & $71-80$ & $-76 * * *$ & 8 & $-103 * * *$ & 13 & $-91 * * *$ & 17 \\
\hline 8 & $81-90$ & $-123 * * *$ & 10 & $-125 * * *$ & 14 & $-113 * * *$ & 18 \\
\hline 9 & $91-100$ & $-150 * * *$ & 13 & $-152 * * *$ & 15 & $-119 * * *$ & 20 \\
\hline 10 & $101-110$ & $-149 * * *$ & 15 & $-155 * * *$ & 17 & $-135 * * *$ & 21 \\
\hline 11 & $111-120$ & -167 **** & 17 & $-163 * * *$ & 18 & $-166 * * *$ & 24 \\
\hline
\end{tabular}

${ }^{1} \mathrm{DD}_{\mathrm{i}}-\mathrm{DD}_{4}=$ Mean yield for DD category $\mathrm{i}_{\mathrm{i}}$ minus mean yield for DD category ${ }_{4}, \mathrm{i}=1$ to $11 . P$-values correspond to a two-tailed $t$-test for the null hypothesis of no difference between category $i$ and category 4 .

${ }^{2} \mathrm{DD}_{\mathrm{i}}-\mathrm{DD}_{3}=$ Mean yield for DD category $\mathrm{i}_{\mathrm{i}}$ minus mean yield for DD category, $\mathrm{i}=1$ to 11 . $P$-values correspond to a two-tailed $t$-test for the null hypothesis of no difference between category $i$ and category 3 .

$* P<0.05 ; * * P<0.01 ; * * * P<0.001$.

proved health in early lactation, as has been speculated by several researchers (Remond et al., 1992; Gulay et al., 2003; Grummer and Rastani, 2004; Rastani et al., 2005).

Research has shown that dry-off decisions (length of dry period) are based at least in part on factors such as days open and milk yield; that is, there is intentional variation within herd in dry period length (Kuhn et al., 2005a). For farmers wishing to implement shortened DD for part of the herd, it will be important to bear in mind that cows given dry periods less than $60 \mathrm{~d}$ will produce less milk in the following lactation than cows given a full 60-d dry period. Therefore, to capitalize on potential benefits of shortened DD, cows that receive fewer DD will need to be culled less intensely than herd mates that may have received longer dry periods, otherwise cows with $\mathrm{DD}<60$ will not be competitive in terms of lifetime production.

Although recent DD research has focused almost exclusively on the consequences of dry periods shorter than $60 \mathrm{~d}$, one of the most pronounced results in Tables 5 through 7 is the amount of lost lifetime production associated with dry periods more than $60 \mathrm{~d}$. Cows with 90 or more DD, for example, generally averaged over $4,000 \mathrm{~kg}$ less lifetime milk yield than cows with only 40 to 60 DD. Even cows with only 70 to 90 DD exhibited substantial losses in lifetime yield. About $11 \%$ of all US Holstein lactations have DD $>70$ and about $8 \%$ have DD > 90 (Kuhn et al., 2005a), which implies substantial costs to US dairy producers. This emphasizes the need

Table 7. Effects (kg) of days dry after first lactation (DD1), second lactation (DD2), and third lactation (DD3) on lifetime protein yield, expressed relative to minimum DD category needed to maximize yield

\begin{tabular}{|c|c|c|c|c|c|c|c|}
\hline \multirow{2}{*}{$\begin{array}{l}\text { DD } \\
\text { category }\end{array}$} & \multirow[b]{2}{*}{ DD } & \multicolumn{2}{|c|}{$\mathrm{DD} 1^{1}$} & \multicolumn{2}{|c|}{$\mathrm{DD} 2^{2}$} & \multicolumn{2}{|c|}{$\mathrm{DD}^{2}$} \\
\hline & & $\mathrm{DD}_{\mathrm{i}}-\mathrm{DD}_{4}$ & $\mathrm{SE}$ & $\mathrm{DD}_{\mathrm{i}}-\mathrm{DD}_{3}$ & $\mathrm{SE}$ & $\mathrm{DD}_{\mathrm{i}}-\mathrm{DD}_{3}$ & $\mathrm{SE}$ \\
\hline 1 & $0-20$ & $-64 * * *$ & 14 & $-100 * * *$ & 24 & $-62 *$ & 30 \\
\hline 2 & $21-30$ & $-26 *$ & 13 & $-49 *$ & 21 & -36 & 25 \\
\hline 3 & $31-40$ & -12 & 7 & 0 & 0 & 0 & 0 \\
\hline 4 & $41-50$ & 0 & 0 & -6 & 10 & -9 & 13 \\
\hline 5 & $51-60$ & 0 & 4 & -15 & 10 & -14 & 12 \\
\hline 6 & $61-70$ & $-10 * *$ & 4 & $-31 * *$ & 10 & -23 & 12 \\
\hline 7 & $71-80$ & -69 **** & 6 & $-88 * * *$ & 11 & $-83 * * *$ & 13 \\
\hline 8 & $81-90$ & $-110 * * *$ & 8 & $-107 * * *$ & 11 & $-107 * * *$ & 15 \\
\hline 9 & $91-100$ & $-131^{* * *}$ & 10 & -130 **** & 12 & -109 **** & 16 \\
\hline 10 & $101-110$ & $-127 * * *$ & 12 & -136 **** & 13 & -127 **** & 17 \\
\hline 11 & $111-120$ & $-141^{* * *}$ & 14 & $-139 * * *$ & 15 & -150 *** & 19 \\
\hline
\end{tabular}

${ }^{1} \mathrm{DD}_{\mathrm{i}}-\mathrm{DD}_{4}=$ Mean yield for $\mathrm{DD}$ category minus mean yield for $\mathrm{DD}$ category ${ }_{4}, \mathrm{i}=1$ to $11 . P$-values correspond to a two-tailed $t$-test for the null hypothesis of no difference between category $i$ and category 4 .

${ }^{2} \mathrm{DD}_{\mathrm{i}}-\mathrm{DD}_{3}=$ Mean yield for DD category $\mathrm{i}_{\mathrm{i}}$ minus mean yield for DD category ${ }_{3}, \mathrm{i}=1$ to 11 . $P$-values correspond to a two-tailed $t$-test for the null hypothesis of no difference between category $i$ and category 3 . $* P<0.05 ; * * P<0.01 ; * * * P<0.001$. 
Table 8. Effects (d) of days dry after first lactation (DD1), second lactation (DD2), and third lactation (DD3) on lifetime DIM, expressed relative to minimum DD category needed to maximize DIM

\begin{tabular}{|c|c|c|c|c|c|c|c|}
\hline \multirow{2}{*}{$\begin{array}{l}\text { DD } \\
\text { category }\end{array}$} & \multirow[b]{2}{*}{ DD } & \multicolumn{2}{|c|}{$\mathrm{DD} 1^{1}$} & \multicolumn{2}{|c|}{$\mathrm{DD} 2^{2}$} & \multicolumn{2}{|c|}{$\mathrm{DD}^{2}$} \\
\hline & & $\mathrm{DD}_{\mathrm{i}}-\mathrm{DD}_{4}$ & SE & $\mathrm{DD}_{\mathrm{i}}-\mathrm{DD}_{3}$ & $\mathrm{SE}$ & $\mathrm{DD}_{\mathrm{i}}-\mathrm{DD}_{3}$ & $\mathrm{SE}$ \\
\hline 1 & $0-20$ & $-37 * *$ & 13 & $-66 * *$ & 22 & -28 & 26 \\
\hline 2 & $21-30$ & -13 & 12 & -37 & 19 & -29 & 24 \\
\hline 3 & $31-40$ & -7 & 6 & 0 & 0 & 0 & 0 \\
\hline 4 & $41-50$ & 0 & 0 & -15 & 9 & -18 & 12 \\
\hline 5 & $51-60$ & -4 & 3 & $-21 * *$ & 9 & $-26^{*}$ & 11 \\
\hline 6 & $61-70$ & $-17 * * *$ & 4 & $-37 * * *$ & 9 & $-36 * *$ & 11 \\
\hline 7 & $71-80$ & $-63 * * *$ & 6 & $-82 * * *$ & 10 & $-81 * * *$ & 12 \\
\hline 8 & $81-90$ & $-91 * * *$ & 8 & $-96 * * *$ & 10 & $-96 * * *$ & 13 \\
\hline 9 & 91-100 & $-109 * * *$ & 9 & $-119 * * *$ & 11 & $-94 * * *$ & 14 \\
\hline 10 & $101-110$ & -117 *** & 11 & -120 **** & 12 & $-105 * * *$ & 15 \\
\hline 11 & $111-120$ & $-120 * * *$ & 12 & $-129 * * *$ & 13 & $-132 * * *$ & 17 \\
\hline
\end{tabular}

${ }^{1} \mathrm{DD}_{\mathrm{i}}-\mathrm{DD}_{4}=$ Mean yield for DD category $\mathrm{i}_{\mathrm{i}}$ minus mean yield for $\mathrm{DD}$ category ${ }_{4}, \mathrm{i}=1$ to $11 . P$-values correspond to a two-tailed $t$-test for the null hypothesis of no difference between category $i$ and category 4 .

${ }^{2} \mathrm{DD}_{\mathrm{i}}-\mathrm{DD}_{3}=$ Mean yield for DD category minus mean yield for DD category, $\mathrm{i}=1$ to $11 . P$-values correspond to a two-tailed $t$-test for the null hypothesis of no difference between category $i$ and category 3 .

$* P<0.05 ; * * P<0.01 ; * * * P<0.001$.

for improved fertility because a primary cause of long dry periods is long days open (Kuhn et al., 2005a).

Presumably, most cows with long dry periods are kept, rather than culled, out of virtual necessity for maintaining herd size. An important note then is that part of the lost lifetime yield associated with long DD is also production lost in the subsequent lactation; cows with DD > 70 have lower production in the following lactation than cows with 60 DD (Kuhn et al., 2005b, 2006). Improved longevity would allow more culling on cows that are currently allowed long dry periods instead. However, until such culling is feasible, research on optimal management for long dry periods may benefit dairy farmers, if for example, the lost production following long DD was due to excess body condition gained during an extended dry period.

Effects of DD, for lactations 1 through 3, on lifetime DIM are in Table 8 . The simple correlation between lifetime DIM and lifetime milk yield was $94 \%$. Therefore, the general pattern of results for lifetime DIM was the same as that for lifetime milk. Dry periods less than $60 \mathrm{~d}$ after first lactation have no benefit for productive life, even though $40 \mathrm{DD}$ after first lactation is largely adequate to ensure no loss in productive life. For second and later lactations, approximately 40 DD maximizes lifetime DIM with only minor losses for dry periods up to $60 \mathrm{DD}$.

\section{Contrast of Adjacent Lactation and Lifetime Results}

The DD effects presented in Tables 4 (sum across adjacent lactations) and 5 (lifetime milk yield) appear to present somewhat contradictory results. As an example, Table 4 shows clear and sizeable losses up to at least $50 \mathrm{DD}$ for dry periods after second and third lactations but yet the results for lifetime yield (Table 5) show a maximum at 31 to $40 \mathrm{DD}$ for the same lactations. How can it be, then, that at least 50 DD would be needed to maximize yield across second and third lactations and yet $30 \mathrm{DD}$ would be adequate to maximize lifetime yield? The answer lies in Table 8. Although cows with dry periods of 50 to $60 \mathrm{~d}$ produce more total milk across second and third lactations, they also have fewer lifetime DIM and, consequently, lower lifetime yield. This emphasizes the importance of examining DD effects on lifetime yield in addition to simply identifying DD to maximize production across adjacent lactations.

These results also present the question as to why cows with shorter dry periods would have greater productive life, especially because they also have lower yield in subsequent lactation. The answer is that the lower yield in subsequent lactation, associated with shorter DD, is also accompanied by fewer days open (Gumen et al., 2005; Kuhn et al., 2006) and better fertility results in longer productive life (VanRaden et al., 2004). It should be noted, however, that this complicates, somewhat, the issue of an economically optimum dry period because the apparent "benefit" to fertility, in lactations following dry periods $<60 \mathrm{~d}$, is due entirely to lower production (Kuhn et al., 2006). Thus, 2 opposing traits are at work in regard to effects of DD on lifetime yield; milk yield is less in lactations following dry periods < 60 d (Annen et al., 2004; Madsen et al., 2004; Gulay et al., 2005; Kuhn et al., 2005b; Rastani et al., 2005) and is not, in general, entirely compensated for by more DIM in the previous lactation (Table 4); however, the lower yield in subsequent lactation is also accompanied by better fertility, which results in more 
lifetime DIM. It is emphasized that the phenotypic consequences of shortened dry periods have been established: short DD (30-40 DD) $\rightarrow$ lower milk in subsequent lactation $\rightarrow$ fewer days open in subsequent lactation $\rightarrow$ longer productive life $\rightarrow$ higher lifetime yield and what remains is much more an economic question rather than a question of phenotypic consequences.

Perhaps the best overall recommendation that can be made to producers in regard to dry period length is to first consider their own particular situation (labor, parlor pressure, pen space, feeding regimens, and so on) and if circumstances allow or favor shortened DD then 1) maintain 50 to $60 \mathrm{DD}$ for first-lactation cows because there is little if any benefit to even lifetime performance for $\mathrm{DD}<50$; 2) 30 to $40 \mathrm{~d}$ dry periods after second and later lactations could be beneficial to lifetime performance and can certainly be utilized without detriment to lifetime yield; 3) avoid dry periods less than $30 \mathrm{~d}$ after any lactation; and 4) avoid dry periods longer than $70 \mathrm{~d}$.

\section{CONCLUSIONS}

Milk yield across first and second lactations can be maximized with 41 to $45 \mathrm{DD}$, although there is essentially no loss associated with dry periods longer than $45 \mathrm{~d}$. In contrast, a minimum of $55 \mathrm{DD}$ is needed to maximize milk yield across second and third, and third and fourth lactations. The fewer DD needed after first lactation to maximize combined first and second lactation yields is presumably due to the greater persistency of first-lactation cows.

In contrast to the dry period lengths needed to maximize yield across adjacent lactations, 41 to $50 \mathrm{DD}$ after first lactation and only 31 to $40 \mathrm{DD}$ after second and later lactations are adequate to maximize lifetime production. These shorter dry periods are adequate to maximize lifetime yield because cows with shorter DD have more lifetime DIM. The longer productive life associated with dry periods of 31 to $40 \mathrm{~d}$ is presumably due to the better fertility associated with shorter DD, although the better fertility has been shown in previous research to be due entirely to lower yield. Thus, whether the dry period length that maximizes lifetime yield also maximizes lifetime profit needs further research.

Dry periods less than $30 \mathrm{~d}$, after any lactation, are detrimental to lifetime yield and should be avoided. However, provided the 30 -d minimum dry period length is met, there is little difference in lifetime yield for dry periods up to $60 \mathrm{~d}$ long.

The most pronounced effect of DD on lifetime yield is not for short DD but rather for long DD, especially for dry periods longer than $90 \mathrm{~d}$. Dry periods longer than $90 \mathrm{~d}$ result in over $4,000 \mathrm{~kg}$ less lifetime milk yield than dry periods of 40 to $60 \mathrm{~d}$. Even dry periods of 70 to $80 \mathrm{~d}$ result in about $2,500 \mathrm{~kg}$ less lifetime milk yield. Previous research has shown that long DD are due in part to long days open. These costs in lifetime yield emphasize, therefore, the need for improved fertility and longevity so that long dry periods can be avoided.

\section{REFERENCES}

Animal Improvement Programs Laboratory. 2005. Trend in milk breeding values for Holstein calculated May, 2005. http://aipl. arsusda.gov/dynamic/trend/current/trndx.html Accessed May $23,2005$.

Annen, E. L., R. J. Collier, and M. A. McGuire. 2003. Older cows fared well without a dry period. Hoard's Dairyman. 148:650.

Annen, E. L., R. J. Collier, M. A. McGuire, J. L. Vicini, J. M. Ballam, and M. J. Lormore. 2004. Effect of modified dry period lengths and bovine somatotropin on yield and composition of milk from dairy cows. J. Dairy Sci. 87:3746-3761.

Bachman, K. C. 2002. Milk production of dairy cows treated with estrogen at the onset of a short dry period. J. Dairy Sci. 85:797-803.

Bachman, K. C. 2004. Will shorter dry periods pay for you? Hoard's Dairyman. 149:321.

Bachman, K. C., and M. L. Schairer. 2003. Invited Review: Bovine studies on optimal lengths of dry periods. J. Dairy Sci. 86:3027-3037.

Coppock, C. E., R. W. Everett, R. P. Natzke, and H. R. Ainslie. 1974. Effect of dry period length on Holstein milk production and selected disorders at parturition. J. Dairy Sci. 57:712-718.

Dias, F. M., and F. R. Allaire. 1982. Dry period to maximize milk production over two consecutive lactations. J. Dairy Sci. 65:136-145.

Funk, D. A., A. E. Freeman, and P. J. Berger. 1987. Effects of previous days open, previous days dry, and present days open on lactation yield. J. Dairy Sci. 70:2366-2373.

Grummer, R. 2004. Here's more on short dry periods. Hoard's Dairyman. 149:142.

Grummer, R. R., and R. R. Rastani. 2004. Why reevaluate dry period length? J. Dairy Sci. 87(E. Suppl.):E77-E85.

Gulay, M. S., M. J. Hayen, K. C. Bachman, T. Belloso, M. Liboni, and H. H. Head. 2003. Milk production and feed intake of Holstein cows given short (30-d) or normal (60-d) dry periods. J. Dairy Sci. 86:2030-2038.

Gulay, M. S., M. J. Hayen, H. H. Head, C. J. Wilcox, and K. C. Bachman. 2005. Milk production from Holstein half udders after concurrent thirty- and seventy-day dry periods. J. Dairy Sci. 88:3953-3962.

Gumen, A., R. R. Rastani, R. R. Grummer, and M. C. Wiltbank. 2005. Reduced dry periods and varying prepartum diets alter postpartum ovulation and reproductive measures. J. Dairy Sci. 88:2401-2411.

Kuhn, M. T., and J. L. Hutchison. 2005. Methodology for estimation of days dry effects. J. Dairy Sci. 88:1499-1508.

Kuhn, M. T., J. L. Hutchison, and H. D. Norman. 2005a. Characterization of days dry in US Holsteins. J. Dairy Sci. 88:1147-1155.

Kuhn, M. T., J. L. Hutchison, and H. D. Norman. 2005b. Minimum days dry to maximize milk yield in subsequent lactation. Anim. Res. 54:351-367.

Kuhn, M. T., J. L. Hutchison, and H. D. Norman. 2006. Days dry effects on subsequent lactation fat, protein, fertility, and somatic cell score. J. Dairy Res.73(2):154-162.

Linderoth, S. 2003. Decrease dry periods by 20 days. Dairy Herd Management. Online. Available: http://www.dairyherd.com Accessed Oct. 12, 2004.

Madsen, T. G., J. B. Andersen, K. L. Ingvartsen, and M. O. Nielsen. 2004. Continuous lactation in dairy cows: Effects on feed intake, milk production and mammary nutrient extraction. J. Anim. Feed Sci. 13:503-506. 
Makuza, S. M., and B. T. McDaniel. 1996. Effects of days dry, previous days open, and current days open on milk yields of cows in Zimbabwe and North Carolina. J. Dairy Sci. 79:702-709.

Mohr, P. 2004. 60 days dry-Says who? Dairy Today. Online. Available: http://www.agweb.com/pub_get_article.asp?sigcat=dairy\& pageid=1063 73 Accessed Oct. 12, 2004.

Rastani, R. R., R. R. Grummer, S. J. Bertics, A. Gümen, M. C. Wiltbank, D. G. Mashek, and M. C. Schwab. 2005. Reducing dry period length to simplify feeding transition cows: Milk production, energy balance, and metabolic profiles. J. Dairy Sci. 88:10041014.

Rastani, R., and R. Grummer. 2003. Shorter dry periods look good. Hoard's Dairyman 148:599.

Remond, B., A. Ollier, and G. Miranda. 1992. Milking of cows in late pregnancy: Milk production during this period and during the succeeding lactation. J. Dairy Res. 59:233-241.

Remond, B., J. Rouel, N. Pinson, and S. Jabet. 1997. An attempt to omit dry period over three consecutive lactations in dairy cows. Ann. Zootech 46:399-408.
Sargent, F. D., V. H. Lytton, and O. G. Wall Jr. 1968. Test interval method of calculating dairy herd improvement association records. J. Dairy Sci. 51:170-179.

Shook, G. E., L. P. Johnson, and F. N. Dickinson. 1980. Factors for improving accuracy of estimates of test-interval yield. DHI Lett. $56: 9-24$.

Sorensen, J. T., and C. Enevoldsen. 1991. Effect of dry period length on milk production in subsequent lactation. J. Dairy Sci. 74:1277-1283.

Stanton, T. L., L. R. Jones, R. W. Everett, and S. D. Kachman. 1992. Estimating milk, fat, and protein lactation curves with a test day model. J. Dairy Sci. 75:1691-1700.

VanRaden, P. M., A. H. Sanders, M. E. Tooker, R. H. Miller, H. D. Norman, M. T. Kuhn, and G. R. Wiggans. 2004. Development of a national genetic evaluation for cow fertility. J. Dairy Sci. 87:2285-2292.

Welper, R. D., and A. E. Freeman. 1992. Genetic parameters for yield traits of Holsteins including lactose and somatic cell score. J. Dairy Sci. 75:1342-1348. 